\title{
Advertisements in Various Television Channels on Food items \& Understandability of Telecasted Programs Influencing Nutritional Status of Urban Graduate Mothers
}

\author{
Ayesha Begum $^{1 *}$, Sonia Zebsyn ${ }^{2}$ and Md. Aminul Haque Bhuyan ${ }^{3}$ \\ Department of Applied Food Science and Nutrition, Faculty of Food Science and \\ Technology, Chittagong Veterinary and Animal Sciences University ${ }^{1}$
}

Assistant Professor, National University, Gazipur²

Institute of Nutrition and Food Science, University of Dhaka ${ }^{3}$

\begin{abstract}
:
A descriptive cross sectional study was carried out amongst eighty graduate mothers having U-5 years children from different socio-economic groups of Mohammadpur area in Dhaka city. They were interviewed on nutrition related programs thorough television. The purpose of the study was to determine the impact of advertisements and understandability of nutrition education programs through different TV channels among the respondents and also the impact of these programs on maternal and child nutrition (MCN). Results of the study showed that the programs of mass media like TV on nutritional aspects influence the nutritional awareness of the respondents. Most of the graduate mothers practiced extra diet as special food taken during pregnancy and lactation period of which television was the major source of knowledge compared to radio, newspaper, doctor and family members. Again 52.5\% respondents were normal along with 33.8\% respondents were overweight and rests of $13.7 \%$ mothers were obese. Furthermore, $82 \%$ U5C's nutritional status were normal whereas only 3\% were found in border line according to MUAC. Few U-5 children were found overweight by WAZ. So adult and child overweight are increasing day by day in urban areas which need great attention to prevent chronic diseases. From this study, it was revealed that no relationship exist between family income and nutritional status of the respondents and also between the educational level and nutritional status of them ( $\mathrm{P}$ value $>$ 0.05). It may be concluded from the study that the exposure to nutrition related programs through different television channels had a role to improve the nutritional status.
\end{abstract}

Key words: Maternal and Child Nutrition, Nutrition Education Program, Nutritional Status, KAP.

Bangladesh Journal of Nutrition. Vol. 24-25 December, 2011-2012. Institute of Nutrition and Food Science, University of Dhaka, Dhaka-1000, Bangladesh.

* Author for Correspondence 


\section{Introduction:}

Bangladesh is the most densely populated country in the world with over 143 million people, half of whom are below poverty level and of which 65 million are children and live in 1, 47,570 square Kilometer area. As proportion of Bangladeshi, in urban areas is projected to increase from 23.9 per cent to 29.6 per cent in $2015^{1}$. Therefore, a tremendous pressure would be put on housing, sanitation, health, education and overall infrastructure in the urban areas. Majority of this vast population is extremely poor. There are more than 36 million people living in poverty $^{2}$. In 2007, urban population was $26 \%^{3}$. Regardless, urban life has been associated with undesirable changes in behavior especially regarding dietary habits and physical activities - factors that are significantly related to obesity ${ }^{4}$.

Our country is a developing country with a high rate of female illiteracy. Female adult literacy rate was $49.1 \%$. Lack of nutritional knowledge amongst the mother is virtually reflected among their children, so our country is burdened with large number of malnourished children ${ }^{5}$. A good mother is a prerequisite for a good nation. To be a good mother she must have proper education and should possess knowledge about the common aspects of health especially on nutrition. So that she can apply her knowledge in the sound bringing of her off spring in all respect. As the country's greater portion of the female population of reproductive age are devoid of education, they have to be offered informal education specially on nutrition and health by various ways and means. Widespread malnutrition throughout the country is a significant public health problem as well as hindrance to national development. Particularly under five year children and woman are the worst victims of hunger and malnutrition. To prevent malnutrition, mass media (TV) plays an important role in improving nutritional knowledge of graduate mothers through dissemination of nutritional knowledge and information. The programs of different TV channels(BTV, Channel i, ATN Bangla, NTV, Bangla vision, etc.) are frequently telecast and these programs focus on health, population control, education, sanitation, cleanlineness, water purification etc. Nutrition education is an essential component to improve nutritional status of a population and is crucial for the wellbeing of the people in general ${ }^{6}$. Nutrition education is defined as "any set of learning experiences designed to facilitate voluntary adoption of eating and other nutrition related behavior conducive to health and well-being” 7 . It will be a key major component in health promotion, as we seek to keep people well rather than merely treat the sick.

As graduate mothers are educated so they can easily understand the position and reasons of lacking behind of their food behavior and they can also get benefits from the currently telecast nutrition education programs through different TV channels and these programs also help them to improve the health status of their children. The mass media plays an important role in everyday life. It is easy to convey knowledge and information to general people through mass media. When TV 
programs are considered it is marked that at least one or two programs are telecast each day. For attracting general people on nutritional aspects, some nice advertisements are shown. These advertisements are generally based on vitamin and mineral deficiency, common diseases, maternal and child care practices etc. In some of these programs, answers are given to the pre- selected questions asked by the conductors of radio and television programs. However, there exists a need to systematically undertake study regarding the effectiveness of different programs through various television channels in order to recommend appropriate improvement in the conduct of those programs for better understandability of the telecast programs in future. With this general view and observation, the present study has been undertaken.

\section{Objectives:}

\section{General objective:}

1. To understand the relationship between the nutritional status of the graduate mothers and their understandability of nutrition education programs on food items through different television channels.

\section{Specific objectives:}

1. To assess the existing nutritional knowledge of the respondents (graduate mothers) through listening and viewing nutrition education programs telecast through different television channels.

2. To observe the anthropometric status of mothers and U-5 children in relation to height, weight, MUAC, and age.

3. To study the impact of nutrition-related telecasted programs on the food habit of mothers and children.

4. To compare/correlate if nutritional status is associated with education level of mothers.

\section{Methodology:}

\section{Study location:}

The location was selected for the study purpose from Mohammadpur area of Dhaka city.

\section{Study population:}

The unit of study was graduate mothers of different socio-economic classes, had at least one under five year children and had television in their homes. 


\section{Study Design:}

The study was cross sectional as it was conducted at one point of time among the selected population.

\section{Research Design: Descriptive}

\section{Sample size:}

Eighty graduate mothers were selected randomly from Mohammadpur area of Dhaka city as respondents as per statistical formula of sample size collection. Their responses were recorded on the questionnaire.

\section{Study period:}

The study including data collection, analysis and write up was carried out during the months of September to December 2010. All the interviews were undertaken by direct contact method.

\section{Development of questionnaire:}

An initial questionnaire was prepared based on the objectives and it was further modified and finalized in accordance with the study objectives and suitability. The questionnaire was pre-tested among another similar (if not identical) group of graduate mothers in order to measure the understandability, responsiveness and comprehensibility of the questionnaire and based on the responses, finally the questionnaire was modified. Anthropometric measurements were taken also to assess the nutritional status of the mothers and the children.

\section{Study Instruments:}

- Questionnaire: It consisted of both close and open ended questions to collect information on the four following aspects.
A. Socio-economic information
B. Anthropometric information
C. Information on television programs
D. Feeding pattern (Including respondent's knowledge, attitude and practice towards health and nutrition)

\section{- $\quad$ Others research instruments used to collect data in the field :}

For measuring anthropometric parameters of mothers and children, the following instruments were used.
a) Wooden height scale: For height measurement
b) Bathroom scale : For weight measurement
c) MAC tape: For mid upper arm circumference measurement of under five years children.


- Collection of Data:

Data were collected from $1^{\text {st }}$ October to $20^{\text {th }}$ October, 2010 using direct

(Face-to-face) interviews.

\section{- $\quad$ Fill in the questionnaire:}

Interviews took place right at the residences of respective mothers and some from the schools where they had been during that time. All the responses were recorded absolutely as the mothers provided. All collected data-sheets were preserved cautiously kept in plastic covers within a field bag to protect those from rain, sun and dust.

- Collection of anthropometric data:

a) Body weight: To record the subject's body weight, a standardized bathroom scale was used. The balance was calibrated to standardize every day. Body weight (kilogram) was recorded by standing on the weighing machine on bare footed and light clothes. In case of under five years children especially who are unable to stand (infant) including less cooperative ones were weighed together with their mothers and then weight of the child was obtained by subtracting the weight of the mother.

b) Height: Height (centimeter) of the subjects was measured bare footed in standing position with a wooden height scale.

c) Left Mid Upper Arm Circumference (L-MUAC): MUAC is the circumference of left upper arm, measured at the mid-point between the olecranon process of ulna and acromial process of scapula of relaxed left arm in hanging position. MUAC was measured using a specialized non-stretchable tape designed for this purpose (like TALC tape developed by the London School of Hygiene and Trop Medicine).

d) Body mass index (BMI)

BMI of the mothers was calculated from the body weight in $\mathrm{kg}$ and height in meter square by using the following formula.

$$
\mathrm{BMI}=\frac{\text { Weight in } \mathrm{Kg}}{\text { Height in (meter) }^{2}}
$$




\section{- Data processing and Data analysis:}

The data in the questionnaire were first checked, cleaned and entered into the computer from the numerical codes on the forms. The data were edited if there were any discrepancy (Double entry, wrong entry, missing, etc.) The frequency distribution for all variables entered was run at first instance and then checked using SPSS 10 Windows program. Relevant statistical tests were carried out for the analysis of data. Both qualitative and quantitative aspects of data were analyzed. The analysis was followed descriptive to inferential statistics.

Results: A total of eighty respondents participated in the study from Mohammadpur area of Dhaka city. The information obtained from the respondents is shown here in consecutive tabular and figurative form.

\section{Socio-demographic characteristics of respondents}

Figure - 1: Distribution of respondents according to their educational level $(\mathbf{n}=\mathbf{8 0})$

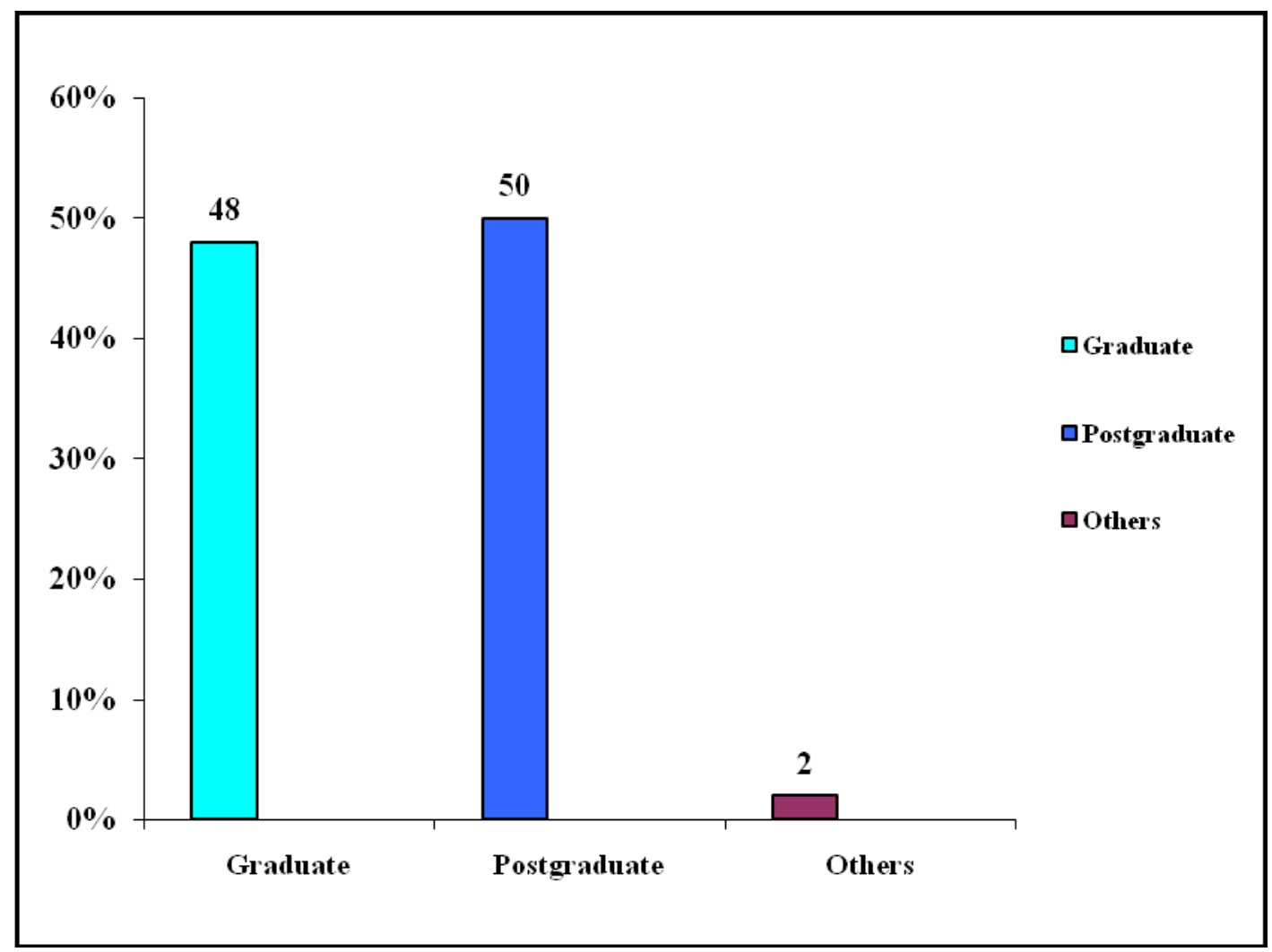

This Figure demonstrates the educational level of respondent. Forty eight percent respondents were graduate, $50 \%$ post graduate and $2 \%$ had more advanced degrees like Ph.D., M. Phil etc. 
II. Probable impact of nutrition-related telecast programs on mother's (KAP) and child's nutritional status.

Table -1: The influence of advertisements on children's feeding pattern $(\mathbf{n}=\mathbf{8 0})$

\begin{tabular}{|l|c|c|}
\hline Advertisements on products & Frequency & Percent of responses* \\
\hline Chocolate & 41 & 51.3 \\
\hline Complan & 23 & 28.8 \\
\hline Nido ( milk powder) & 9 & 11.3 \\
\hline Maggi noodles & 19 & 23.8 \\
\hline Soft drinks & 25 & 31.3 \\
\hline Pran mango juice & 11 & 13.8 \\
\hline Pran frutoo & 10 & 12.5 \\
\hline Pran potato chips & 12 & 15 \\
\hline Lays chips & 3 & 3.8 \\
\hline Junior Horlicks & 21 & 26.3 \\
\hline Corn flex & 9 & 11.3 \\
\hline Shakti dai & 11 & 13.8 \\
\hline Biscuit & 7 & 8.8 \\
\hline Others & 5 & 6.3 \\
\hline
\end{tabular}

Table-1 shows the influence of different types of advertisements on feeding pattern of children in which advertisement of chocolate (51.3\%) had profound impact. (*Here responses were of multiple natures)

Figure - 2: Distribution of respondents by their understandability of current health and nutrition programs

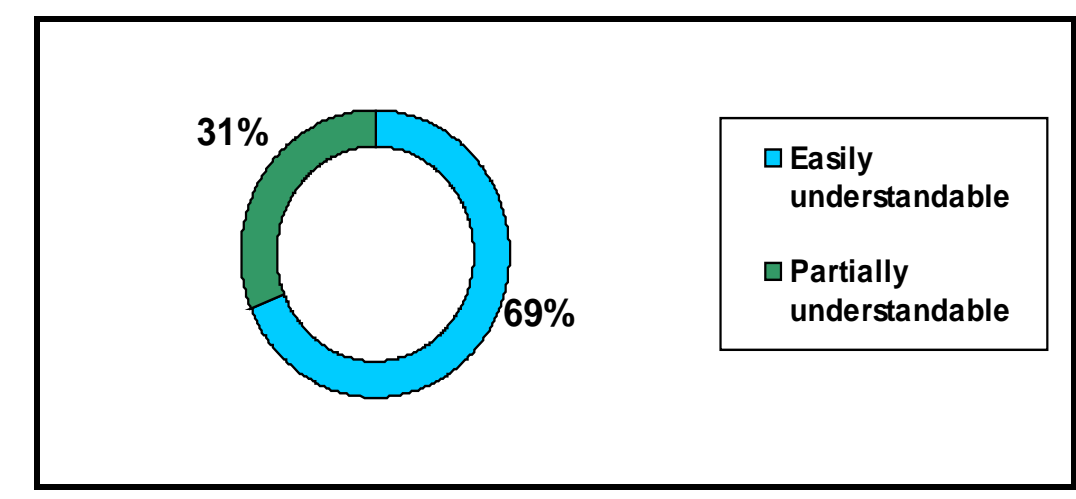

Sixty nine percent respondents easily understood current health and nutritional programs is indicated by this figure. 
Bangladesh J. Nutr. Vol. 24-25 Dec 2011-2012

Table - 2: Distribution of respondents by their ability to recall at least one or more messages learnt from television $(n=80)$

\begin{tabular}{|l|c|c|}
\hline Type of message & Frequency & Percent of responses* \\
\hline Use of iodized salt & 72 & 90 \\
\hline Importance of colostrum & 33 & 41.3 \\
\hline $\begin{array}{l}\text { Nutrient contents of } \\
\text { different food }\end{array}$ & 40 & 50 \\
\hline Balanced diet & 59 & 73.8 \\
\hline Drinking safe water & 75 & 93.8 \\
\hline $\begin{array}{l}\text { Advantages of breast } \\
\text { feeding }\end{array}$ & 25 & 31.3 \\
\hline Proper cooking & 41 & 51.3 \\
\hline Geriatric nutrition & 17 & 21.3 \\
\hline $\begin{array}{l}\text { Preventive measures of } \\
\text { nutritional deficiency } \\
\text { diseases }\end{array}$ & 21 & 26.3 \\
\hline Others & 15 & 18.8 \\
\hline
\end{tabular}

“Drinking safe water” this message was learnt by maximum respondents (93.8\%) while only $21.3 \%$ respondents learnt "geriatric nutrition" from television. (* Responses were of multiple natures)

Table-3: Distribution of respondents by their source of knowledge on nutritional deficiency diseases

\begin{tabular}{|l|c|c|}
\hline Source & Frequency & Percent of responses* \\
\hline Newspaper & 25 & 31.3 \\
\hline Television & 75 & 93.8 \\
\hline Radio & 12 & 15 \\
\hline Study & 28 & 35 \\
\hline Other & 17 & 21.3 \\
\hline
\end{tabular}

Hundred percent respondents heard the names of nutritional deficiency diseases in which 93.8\% respondents were getting their knowledge on nutritional deficiency diseases from television where $15 \%$ from radio was the lowest. (* Here responses were of multiple natures) 
Figure-3: Distribution of respondents according to their opinion to prevent nutritional deficiency diseases

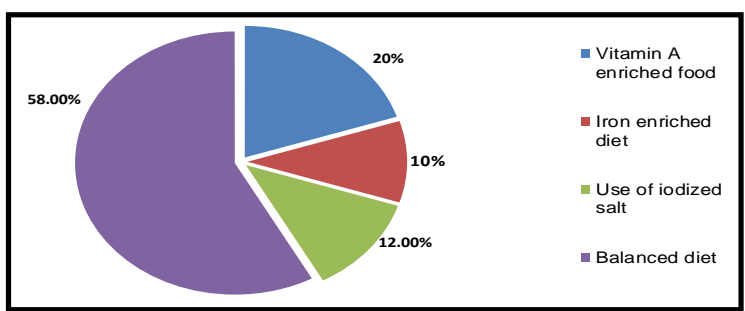

This figure demonstrates the opinion of respondents to prevent nutritional deficiency diseases by taking nutritious food. About $58 \%$ graduate mothers suggested to take balanced diet to prevent nutritional deficiency diseases.

Figure - 4: Source regarding conception of taking special food as extra diet during pregnancy

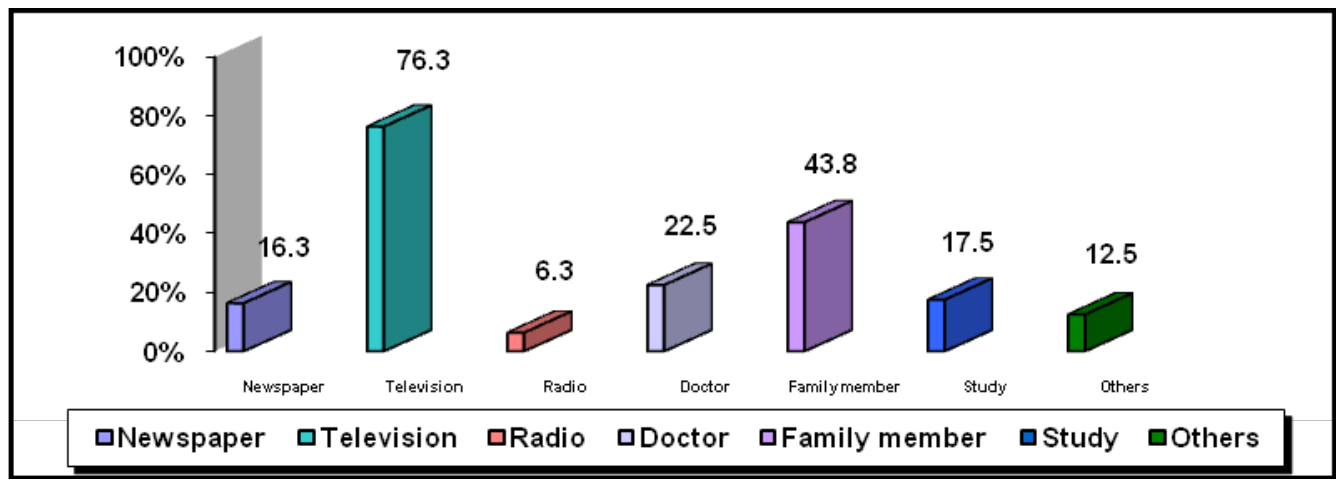

Regarding the source of conception of food delivery and extra diet during pregnancy, TV was the major source for $76.3 \%$ respondents whereas Radio was the source for only $6.3 \%$ respondents.

Table - 4: Distribution of U5C's nutritional status by different categories of left middle upper arm circumference (LMUAC)

\begin{tabular}{|l|c|c|c|l|}
\hline LMUAC(cm) & $\begin{array}{l}\text { Percentage } \\
\text { (Male) }\end{array}$ & Percentage(Female) & Total (\%) & $\begin{array}{l}\text { Nutritional } \\
\text { status }\end{array}$ \\
\hline$<11$ & 0.00 & 0.00 & 0.00 & Severe \\
\hline 11 to 12.49 & 0.00 & 0.00 & 0.00 & Moderate \\
\hline 12.5 to 13.49 & 0.00 & 3 & 3 & Borderline \\
\hline$>13.5$ & 25 & 57 & 82 & Normal \\
\hline Total & 25 & 60 & 85 & \\
\hline
\end{tabular}

This figure shows that $82 \%$ U5C's nutritional status were normal where $3 \%$ U-5 children were found in border line. 
Table-5: Association of number and percent distribution between nutritional status and education level of graduate mothers

\begin{tabular}{|l|l|l|l|l|}
\hline \multirow{2}{*}{$\begin{array}{l}\text { Education level } \\
\text { of mothers Nutritional } \\
\text { status }\end{array}$} & \multicolumn{2}{|c|}{ Education level of mothers } & \multirow{2}{*}{ Total } & \multirow{2}{*}{ P value } \\
\cline { 2 - 4 } & Graduate & $\begin{array}{l}\text { Postgraduate } \\
\text { and others }\end{array}$ & \\
\hline $18.5-24.99$ (Normal) & $46.2 \%(18)$ & $53.8 \%(21)$ & $100 \%(39)$ & \multirow{2}{*}{0.468} \\
\hline $25-29.99$ (Overweight) & $40.0 \%(10)$ & $60 \%(15)$ & $100 \%(25)$ & \\
\hline $30-30.99$ (Obese) & $60 \%(10)$ & $40 \%(6)$ & $100 \%(16)$ & \\
\hline Total & $\mathbf{4 6 . 8 \% ~ ( 3 8 )}$ & $\mathbf{5 3 . 2 \% ~ ( 4 2 )}$ & $\mathbf{7 9}(\mathbf{4 0 0})$ & \\
\hline
\end{tabular}

The table shows the relationship between respondent's education level and nutritional status of them. Among them 46.2\% (18) graduate mothers were normal, $40 \%$ graduate mothers were overweight and $60 \%$ graduate mothers were obese. In case of postgraduate and others, 53.8\% mothers had normal nutritional status, $60 \%$ were overweight and $40 \%$ were obese. Here the p- value was > 0.05 ; the test is insignificant which indicates that there was no relationship between nutritional status and education level of graduate mothers.

\section{Discussion:}

The mother of the family is directly related with caring her growing child as well as the adult family members. Bangladesh has one of the highest rates of illiteracy in the world. A large number of people in our country are devoid of even having primary education. To improve the awareness of mothers about the role of nutrition in everyday life and to provide them with information that certain nutritional disease may arise due to the lack of specific nutrients in their diet. The aim of nutrition for mothers and other family members should focus on various related aspects of nutritional information in order to improve food behavior.

Keeping this view in mind various government and non-government organizations are working at different level in disseminating nutritional knowledge among various population. In order to improve mothers nutritional and health related knowledge, BTV and others Bengali channels such as RTV, NTV, ATN Bangla, ETV, Bangla vision etc. telecast related programs every day. This study was designed to evaluate the influence of these programs on maternal and child nutrition (MCN).

This study was performed in urban areas among graduate mothers having U-5 years children. There were 80 participants in this study. Forty eight percent respondents were graduate, $50 \%$ post graduate and $2 \%$ had more advanced degrees like Ph.D., M. Phil etc.

Hundred percent respondents had television. Seventy three percent respondents watched television regularly where $27 \%$ respondents did it irregularly. It is crucial to assess level of understanding on any programs of health \& nutrition, subjectively or objectively. Sixty nine percent respondents easily understood current health and nutritional program while thirty one percent respondents partially understood. 
Ninety three percent mothers learnt important messages of "Taking safe drinking water" and "Use of iodized salt while cooking or preparing salads", followed by taking balanced diet by 74\% mothers and "Nutrient contents of different foods" and “cooking food properly" by 50.5\% mothers, each, though their answers were often multiple. Different types of advertisement such as advertisement of chocolate, Maggi noodles, junior Horlicks, soft drinks etc affected feeding pattern of children. Among them the advertisement of chocolate 51.3\%, complain (28.8\%), Maggi noodles (23.8\%) had profound effect on children's feeding pattern.

All respondents (graduate mothers) had knowledge on nutritional deficiency disease among them 52.5\% respondents were normal, 33.8\% respondents were overweight and the rest of respondents $13.7 \%$ were obese. Malnutrition is a common picture in our country. Nutrition education for the mothers can improve the situation a lot. In this study it was found that television (93.8\%) was the major source of knowledge about nutritional deficient diseases. Fifty eight respondents suggested balanced diet to prevent nutritional deficiency diseases.

Regarding the source of conception of food delivery and extra diet during pregnancy, TV was the major source for $76.3 \%$ respondents whereas Radio was the source for only $6.3 \%$ respondents. This figure shows that $82 \%$ U5C's nutritional status were normal where $3 \%$ U-5 children were found in border line. Here, the relationship between respondent's education level and nutritional status of them according to different categories of body mass index ${ }^{8}$ was also analyzed where $46.2 \%$ (18) graduate mothers were normal, $40 \%$ graduate mothers were overweight and $60 \%$ graduate mothers were obese. In case of postgraduate and others, 53.8\% mothers had normal nutritional status, $60 \%$ were overweight and $40 \%$ were obese. Here the p- value was $>0.05$; the test is insignificant which indicates that there was no relationship between nutritional status and education level of graduate mothers.

\section{Conclusion:}

Bangladesh- world's one of the most resource constraint least developed countries fights back round-the-year natural disasters and have $\sim 70 \%$ inhabitants abreast struggling for survival at below poverty line. As in Bangladesh resources are limited. Food production cannot meet the nation's requirement. Moreover the purchasing power of our majority population is far below to sustain better nutrition, health and education. In this regards the role of mass media for the country is inevitable. The campaign of mass media about nutrition can create awareness among our population. So the country's limited resources and the hard earned money could be properly utilized to give them optimum nutrients in their diet. Recent literature reveals that role of electronic media remain inevitably costeffective in creating mass-awareness. Since majority of urban mid-level income groups possess television (best emerging communication strategy), this small scale study was conducted among women (and children) just to bring out definite indicators that telecasted nutrition-related programs ultimately having an impact on child's nutrition through frequently reinforcing key messages on health and nutrition aspects. Findings of this study revealed $\sim 95 \%$ mothers acquired a knowledge-base on nutritional deficiencies/disorders from TV-casted programs 
which they practiced during their pregnancy and lactation period. Objectively, such TV-casted program motivated 52.5\% mothers in maintaining a normal BMI and keeping $82 \%$ of their U-5 children's nutrition normal (LMUAC), irrespective of their family income and educational level (In both cases, $P$ value $>0.05$ ). From this study it is evident that electronic media, particularly TV, play an important role in disseminating health information among urban people. Television emerged as the most important mass media for this purpose followed by radio, doctor/ health worker.

However, further large scale studies involving heterogenic sample from geographically diverse communities are thus needed with appropriate design to find out the effectiveness of telecasted nutrition related programs on maternal and child nutrition (MCN) and also for national level nutrition education program planning through television along with other press media in future. This type of research may also supplement the overall proposed policies of the Government to achieve health for all.

\section{References:}

1. Human Development Report, UNDP, 2004; Children's Situation in Bangladesh and Situational analysis (SITAN), pp 20.

2. CIA Fact Sheet on poverty, Washington D.C.,USA; July-2002.

3. State of the World's Children (SOWC), UNICEF - 2009.

4. World Health Organization. Resolution WHA53.23. Diet, physical activity and health. In: Fifty-fifth World Health Assembly. Geneva; 2002.v.1.

5. National Nutrition Survey, Institute of Nutrition and Food Science, University of Dhaka, 1981-82

6. King, F.S., Burgess, A., Nutrition for developing Countries. Second Edition, Oxford University Press, 1996.

7. Contento IR. The effectiveness of nutrition education and implications for nutrition policy, programs and research: A review of research. Journal of Nutrition Education. 1995; 127(5): 284- 286.

8. Mailey KV, Ferro- Luzzi, Use of body mass index of adults in assessing individual and community nutritional status. Bulletin WHO 2005; 73: 673-680. 